\title{
Maximum Torque per Ampere Operation of Brushless Doubly Fed Induction Machines
}

\author{
M. Ahmadian, B. Jandaghi and H. Oraee \\ Center of Excellence in Power System Management and Control, \\ Department of Electrical Engineering, Sharif University of Technology \\ Azadi Ave., Tehran, Iran \\ Phone/Fax number: +98935 460 6644, e-mail: mhd.Ahmadian@gmail.com, behzad_Jandaghi@ee.Sharif.edu, \\ oraee@sharif.edu
}

\begin{abstract}
In this paper, an analytical method for increasing the steady state torque per ampere capability for BDFMs, using equivalent circuit is presented. In this approach, uni-current proposition proposed to define a unique current value for optimization, and find the current angel corresponding to maximum torque. The accuracy of the proposition is verified by simulation. The effect of pole pair number selection of power and control windings on maximum torque is explained by dividing torque expression into synchronous and asynchronous terms. Finally, the optimal current values and optimal torque are achieved. Based on the optimal value of torque, or MTPA index, analytical optimization of machine design is suggested, which can be performed by manipulation of components of the MTPA index.
\end{abstract}

\section{Key words}

Brushless doubly fed machine (BDFM), maximum torque per ampere (MTPA), equivalent circuit model, synchronous frame dq model, uni-current proposition.

\section{Introduction}

BDFM has two uncoupled windings with different pole numbers on the stator. One winding is called power winding ( $2 \mathrm{p}_{1}$ poles), while the other is control winding ( $2 \mathrm{p}_{2}$ poles). The power winding is connected directly to the grid and the control winding is supplied by a bidirectional converter.

Because of the energy cost, electrical machines should operate at maximum efficiency. For the most machine designs, there are two important efficiency indices, maximum efficiency (or minimum loss) and maximum torque per ampere (MTPA).

Maximum machine efficiency occurs, when it has minimum losses at a given torque and speed. A lot of research is done on operation of the induction motor drives at the minimum power loss point [1]-[4]. The copper and core losses are the majority of the total electrical losses in a machine. It is possible to find a compromise between copper and core losses, such that the total loss is minimized.

In converter fed machines, efficient use of the power converter is important, because of the cost of the power converter. At low speeds, this optimization generally requires operating the machine at maximum torque per ampere to achieve high torque output for fast acceleration of the connected load [5]. A maximum torque per
Ampere scheme was proposed by [6] to minimize the stator current and converter rating in certain speeds. Other works are done for maximum torque per ampere capability of IPMSMs [7] and induction motor drives [5], [6].

It was found that neither "minimum loss" nor "maximum torque per ampere" produced optimum machine efficiency, and the optimum efficiency occurred between the two indices [8], [9].

Minimizing the loss is not completely appropriate for a BDFM, since the stator currents are not minimized. As a result, the converter rating and its losses are not minimized. Furthermore, Core loss in a BDFM is not offered yet, so it is impossible to formulate all loss components and analyze them, numerically. Therefore, in this approach, we will neglect core losses, and will try to maximize the torque in fixed current amplitude.

Since shaft speed is not arbitrary in machine operation, stator current minimization should be considered independent of speed regulation [9]. Hence the optimization should be performed at the machine's most frequent operating point. In this paper the torque per ampere optimization performed through maximization of torque by the stator current angle. After that, torquespeed relationship is analyzed for optimal machine operation over different speed ranges. Also, the effect of selecting pole pair numbers of power and control windings on torque is explored. The main achievements of the optimization are found in the final part, where optimal torque value is used for machine design optimization purpose.

\section{BDFM Models}

There are some different models for BDFM including coupled-circuit, synchronous frame d-q-0 model, equivalent circuit and core model. The d-q-0 model is derived from the reduced order coupled-circuit model, and through transformation of this model into symmetrical components, the equivalent circuit model (Fig. 1) is obtained [10]. The core model is simplified version of equivalent circuit model [11].

For ease of analysis, synchronous reference frame d-q model [12] is used, which introduces constant system states in steady state operation of the machine. 


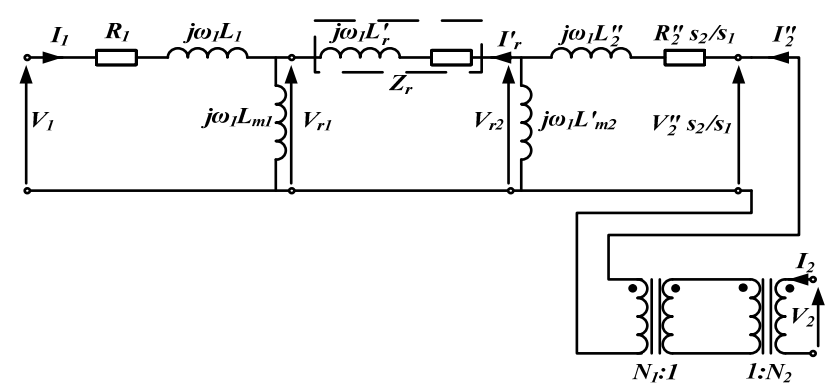

Fig. 1 Steady state per phase equivalent circuit for BDFM

\section{A. Torque Calculations}

Torque equation is derived by authors for MTPA purpose from steady state $\mathrm{d}-\mathrm{q}$ model of BDFM. Equating derivatives of the synchronous frame $\mathrm{d}$-q model to zero, and defining new variables in (2), (3) and (4) results in:

$$
\begin{gathered}
T_{e}=-I_{1}^{2} M_{1_{1}}^{2} p_{1} \frac{R_{r} \omega_{s}}{Z_{r}^{2}}+I_{2}^{2} M_{2_{1}}^{2} p_{2} \frac{R_{r} \omega_{s}}{Z_{r}^{2}} \\
+I_{1} I_{2} M_{1_{1}} M_{2_{1}} \frac{\omega_{s}}{Z_{r}}\left[\begin{array}{c}
\left(p_{2}-p_{1}\right) \operatorname{Cos}(\Psi) \operatorname{Cos}\left(\theta_{1}+\theta_{2}\right) \\
+\left(p_{2}+p_{1}\right) \operatorname{Sin}(\Psi) \operatorname{Sin}\left(\theta_{1}+\theta_{2}\right)
\end{array}\right]
\end{gathered}
$$

where

$$
\begin{aligned}
& I_{i}=\sqrt{\boldsymbol{i}_{i d}^{2}+\boldsymbol{i}_{i q}^{2}}, \theta_{i}=\operatorname{tg}^{-1}\left(\frac{\boldsymbol{i}_{i q}}{\boldsymbol{i}_{i d}}\right) i=1,2 \\
& \omega_{s}=p_{1} \omega_{r}-\omega_{1} \\
& Z_{r}=\sqrt{R_{r}^{2}+\left(\omega_{s} L_{r}\right)^{2}}, \Psi=\operatorname{tg}^{-1}\left(\frac{\omega_{s} L_{r}}{R_{r}}\right)
\end{aligned}
$$

where $\theta_{1}, \theta_{2}$ are power winding and control winding current angles. The Equation is also verified by means of symbolic math toolbox of MATLAB software.

This equation is divided into two parts, synchronous and asynchronous. Synchronous component varies by angles of two stator currents, however asynchronous torque is independent of them. This component has two negating terms, which frustrates itself significantly.

\section{Optimization Variables}

Our goal is to maximize torque per ampere capability. In this optimization procedure, torque value is maximized for constant current values. There are several parameters in torque equation and some of them are related to machine design and are fixed. Hence the stator currents and slip speed are selected as optimization variables.

\section{A. Stator Currents}

In the reduced order $\mathrm{d}-\mathrm{q}-0$ model of BDFM, rotor and stator currents are described by two vector components each. This means that we have at least three different current amplitudes, while a single current value is needed for MTPA purpose.

Uni-current proposition: In the core model, two stator currents $I_{1} \angle \theta_{1}$ and $-I_{2}^{\prime \prime} \angle \theta_{2}$ are assumed equal. This may not remain valid unless three requirements satisfy.
1) Parallel branch inductances should be greater enough than series (leakage) inductances.

2) $\omega_{s}$ and $\omega_{2}$ should be far enough from zero.

3) Phase of $v_{2}$ should be far from phase of $v_{l}$.

The first requirement is achieved in well designed induction machines. For the second condition, value of equivalent stator 2 resistance is proportional to $\left|s_{2} / s_{1}\right|$, or $\omega_{1} / \omega_{2}$, also rotor resistance equals $R_{r}^{\prime}$ divided by $s_{1}=\omega_{s} / \omega_{1}[12]$; so $\omega_{s}$ and $\omega_{2}$ should be far enough from zero, to avoid a large voltage drop on the resistances. Keeping away from natural speed of the machine ( $\left.\omega_{2}=0\right)$, is optimal, since BDFMs are designed for synchronous mode operation. The third condition implies that if the machine is in generating mode, both sources should gain power from the series branches path [11].

The mismatch of the equivalent circuit and the core model is scrutinized by means of equivalent circuit simulation, through defining two indices: "Current Ratio" and "Phase Difference". "Current ratio" is defined as the ratio of power winding current and transferred control winding current, and "phase difference" is the phase between the power winding current angel and negative of control winding current angel. These indices show the accuracy of equating $I_{1} \angle \theta_{1}$ and $-I_{2}^{\prime \prime} \angle \theta_{2}$ in uni-current proposition.

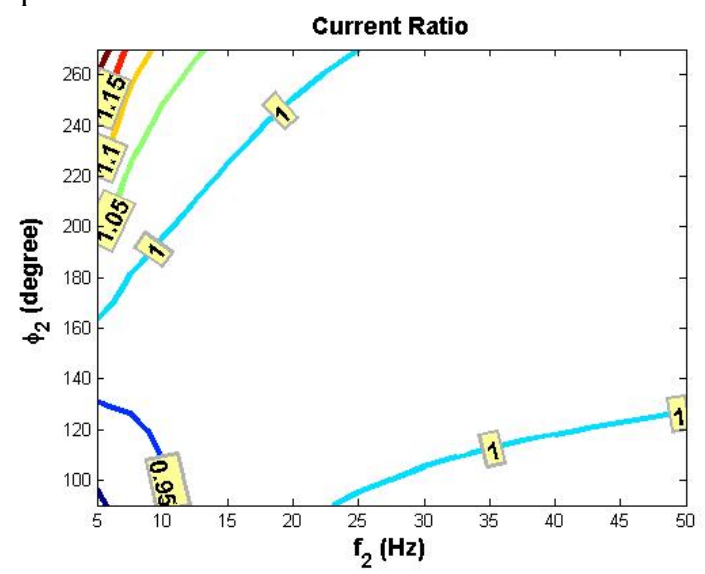

Fig. 2 Current ratio vs. phase and frequency

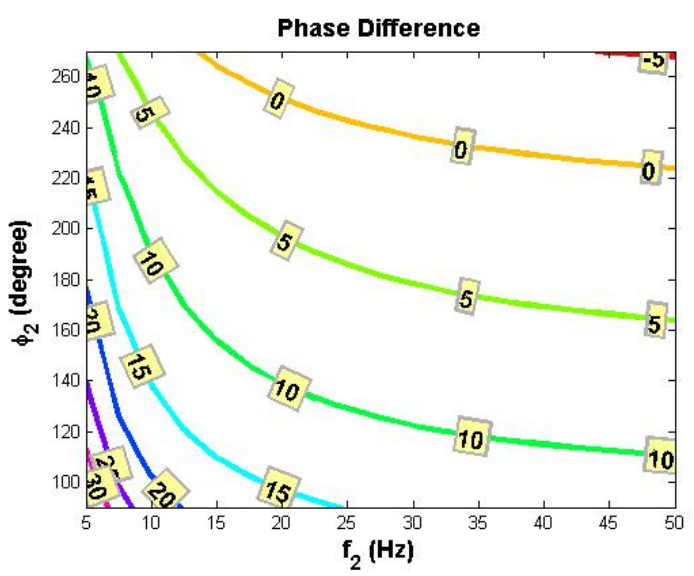

Fig. 3 Phase difference vs. phase and frequency

As shown, the uni-current proposition holds in most simulation regions with $\pm \% 5$ amplitude error. 


\section{B. Slip Speed}

Slip speed, or $\omega_{s}$, is defined as below:

$$
\omega_{s}=p_{1} \omega_{r}-\omega_{1}=\frac{p_{1} \omega_{2}-p_{2} \omega_{1}}{p_{1}+p_{2}}
$$

Assuming $\omega_{1}$ constant and equal to grid frequency, and $\omega_{2}$ variable in range of $\omega_{2} \in\left[0, \omega_{1}\right]$, rotor speed and slip speed would cover following ranges:

$$
\omega_{r} \in\left[\frac{\omega_{1}}{p_{1}+p_{2}}, \frac{2 \omega_{1}}{p_{1}+p_{2}}\right], \omega_{s} \in\left[\frac{-p_{2} \omega_{1}}{p_{1}+p_{2}}, \frac{-\left(p_{2}-p_{1}\right) \omega_{1}}{p_{1}+p_{2}}\right]
$$

It is observed that existence of zero crossing in slip speed directly depends on our choice of connecting $p_{1}$ pole pair to grid or vice versa. If $p_{1}>p_{2}$, then there exist a zero crossing there, else, $\omega_{s}$ always remains negative. Fig. 4 displays $\omega_{s}$ for a $2 / 4$ pole pair machine. The red line (circled) stands for $p_{1}=4>p_{2}=2$ case and blue line shows $p_{1}=2<p_{2}=4$ case.

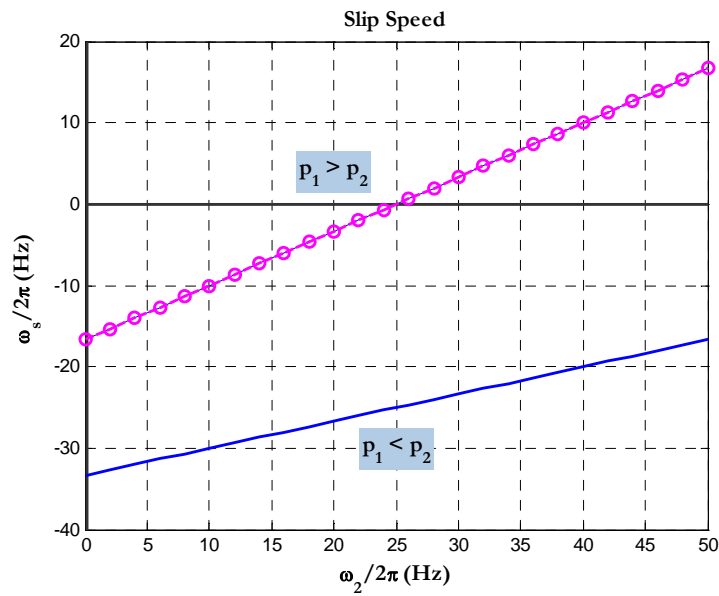

Fig. 4 Slip speed as function of control winding frequency

\section{Torque Optimization}

According to the uni-current proposition, the torque equation can be simplified further:

$$
\begin{gathered}
I_{1}=I_{2}^{\prime \prime}=I \Rightarrow I_{2}=\left(\frac{n_{1}}{n_{2}}\right) I \\
\theta_{1}=\theta_{2}+\pi \\
T_{e}=I^{2}\left[\left(\frac{n_{1}}{n_{2}}\right)^{2} M_{2_{1}}^{2} p_{2}-M_{1_{1}}^{2} p_{1}\right] \frac{R_{r} \omega_{s}}{Z_{r}^{2}} \\
-\frac{n_{1}}{n_{2}} I^{2} M_{1_{1}} M_{2_{1}} \frac{\omega_{s}}{Z_{r}}\left[\begin{array}{l}
\left(p_{2}-p_{1}\right) \operatorname{Cos}(\Psi) \operatorname{Cos}\left(2 \theta_{1}\right) \\
+\left(p_{2}+p_{1}\right) \operatorname{Sin}(\Psi) \operatorname{Sin}\left(2 \theta_{1}\right)
\end{array}\right]
\end{gathered}
$$

\section{A. Angel choice}

The optimization variable is now only $\theta_{1}$. Value of $\theta_{1}$ to set synchronous torque on its maximum value is then:

$$
\theta_{1, m}=\frac{1}{2}\left(k \pi+\operatorname{tg}^{-1}\left[\frac{p_{2}+p_{1}}{p_{2}-p_{1}} \operatorname{tg} \Psi\right]\right)
$$

Substituting Eq. (10) in Eq. (9), maximum of torque is given by:

$$
\begin{aligned}
& T_{e, \max }=I^{2}\left[\left(\frac{n_{1}}{n_{2}}\right)^{2} M_{2_{1}}^{2} p_{2}-M_{1_{1}}^{2} p_{1}\right] \frac{1}{R_{r}} \frac{\omega_{s}}{1+\left(\frac{\omega_{s} L_{r}}{R_{r}}\right)^{2}} \\
& \pm \frac{n_{1}}{n_{2}} I^{2} M_{1_{1}} M_{2_{1}}\left(p_{2}+p_{1}\right) \frac{1}{R_{r}} \frac{\omega_{s}}{\sqrt{1+\left(\frac{\left(p_{2}+p_{1}\right) \omega_{s} L_{r}}{\left(p_{2}-p_{1}\right) R_{r}}\right)^{2}}}
\end{aligned}
$$

The positive or negative sign of synchronous torque determines the motoring or generating torque, settled by value of $k$ in $\theta_{1, m}$ expression.

Torque equation may be split down into two terms now:

$$
T_{e, \max }=T_{\text {asyn }} \pm T_{\text {syn }}
$$

where

$$
\begin{aligned}
& T_{\text {syn }}=T_{0} \frac{\omega_{s}}{\sqrt{1+\left(\frac{\left(p_{2}+p_{1}\right) \omega_{s} L_{r}}{\left(p_{2}-p_{1}\right) R_{r}}\right)^{2}}} \\
& T_{\text {asyn }}=T_{1} \frac{\omega_{s}}{1+\left(\frac{\omega_{s} L_{r}}{R_{r}}\right)^{2}}
\end{aligned}
$$

and

$$
\begin{aligned}
& T_{0}=\frac{n_{1}}{n_{2}} \frac{I^{2}}{R_{r}} M_{1_{1}} M_{2_{1}}\left(p_{1}+p_{2}\right) \\
& T_{1}=\frac{I^{2}}{R_{r}}\left[\left(\frac{n_{1}}{n_{2}}\right)^{2} M_{2_{1}}^{2} p_{2}-M_{1_{1}}^{2} p_{1}\right]
\end{aligned}
$$

Here $T_{s y n}$ represents peak value of synchronous torque, after substitution of angle $\theta_{1, m}$. Positive or negative sign of synchronous torque can be determined by the current angle. Amplitude of asynchronous torque also depends on operation conditions, but it is expected that sum of its positive and negative components become smaller than each.

It should be mentioned, that maximum power per ampere (MPPA) can be easily achieved in this optimization problem by multiplication of rotor speed in torque equation. The derived expression is again in terms of $\omega_{s}$.

\section{B. $\quad$ Torque speed curves}

As pointed out above, it is expected that $T_{0}>T_{1}$ in general. $T_{s y n}$ is strictly increasing function of $\omega_{s}$, while $T_{\text {asyn }}$ has a maximum and a minimum on its domain. The asymptotes of $T_{s y n}$ are $\pm T_{0}$, and it reaches at $\sqrt{2} / 2$ at $\pm \omega_{s 1}^{*}$. The maximum and minimum of $T_{\text {asyn }}$ take place at $\omega_{s 2}^{*}$ and $-\omega_{s 2}^{*}$ respectively, and the unique horizontal asymptote is $T_{a s y n}=0 . \omega_{s 1}^{*}$ and $\omega_{s 2}^{*}$ are defined as:

$$
\omega_{s 1}^{*}=\frac{\left|p_{2}-p_{1}\right|}{p_{2}+p_{1}} \frac{R_{r}}{L_{r}} \text { and } \omega_{s 2}^{*}=\frac{R_{r}}{L_{r}}
$$

Components of torque are shown in Figs. 5 and 6.

Note that $T_{\text {asyn }}$ has the same structure of Kloss equation [13] for three phase induction machines, assuming that slip of induction machines coincides with per unit value of slip speed in BDFM, with base speed of $\omega_{s 2}^{*}$. 


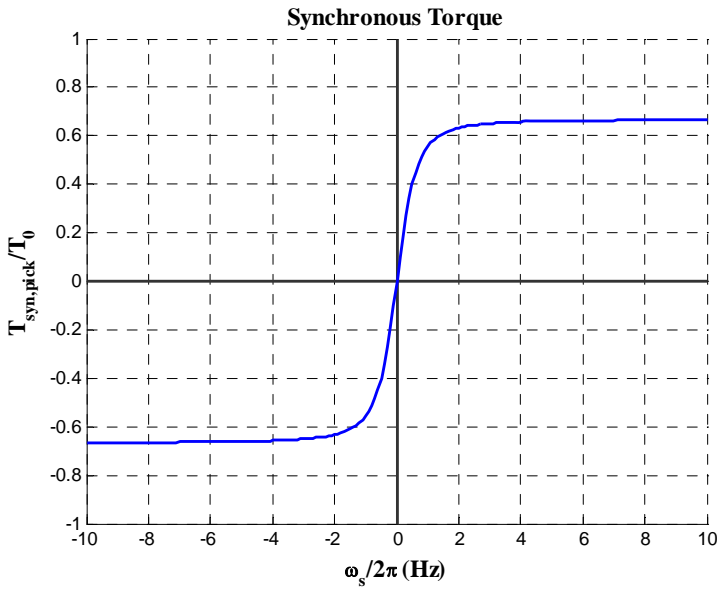

Fig. 5 Synchronous Torque

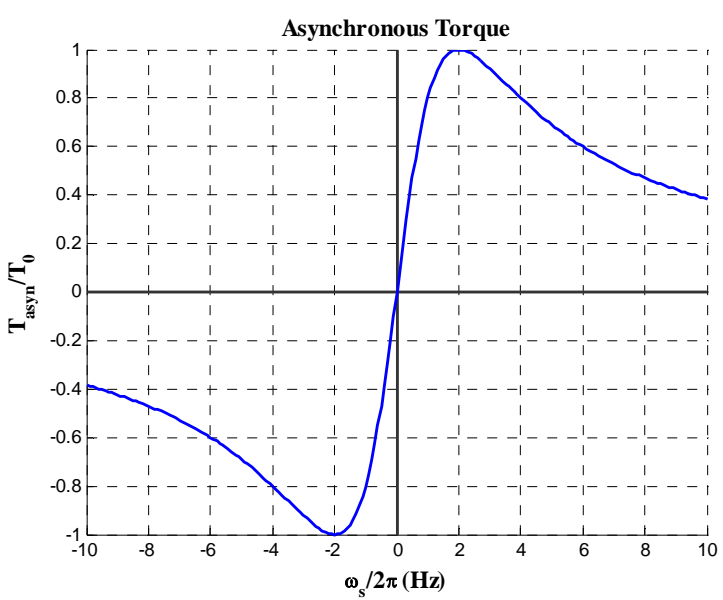

Fig. 6 Asynchronous Torque

According to Fig. 4 , if the $p_{1}<p_{2}$ setup is chosen, the $\omega_{s}=0$ is avoided, hence torque value would not experience zero value in typical speed range. In addition, if $\omega_{1} \gg \omega_{s 2}^{*}>\omega_{s 1}^{*}$, the asynchronous torque is damped well, and torque profile becomes flat. Using parameter values of a D180-frame prototype BDFM [12] results in:

$$
\omega_{s 2}^{*}=\frac{R_{r}}{L_{r}} \simeq 2 \ll \frac{\omega_{1}}{3}=125.6 \mathrm{rad} / \mathrm{sec}
$$

This is a very satisfactory result and accepts the benefit of nested-loop rotor of prototype machine, which offers smaller $R_{r}$ than other rotor designs.

\section{Stator currents for operation in MTPA}

By setting the variables, i.e. current angel and pole pair numbers of power and control windings, on their optimal values for maximum torque per ampere, we can conclude that for $p_{1}<p_{2}$ the power winding current angel should be regulated at about $(2 k+1) \frac{\pi}{4}$ rad. Fig. 7 illustrates the variation of current angel vs. control winding frequency.

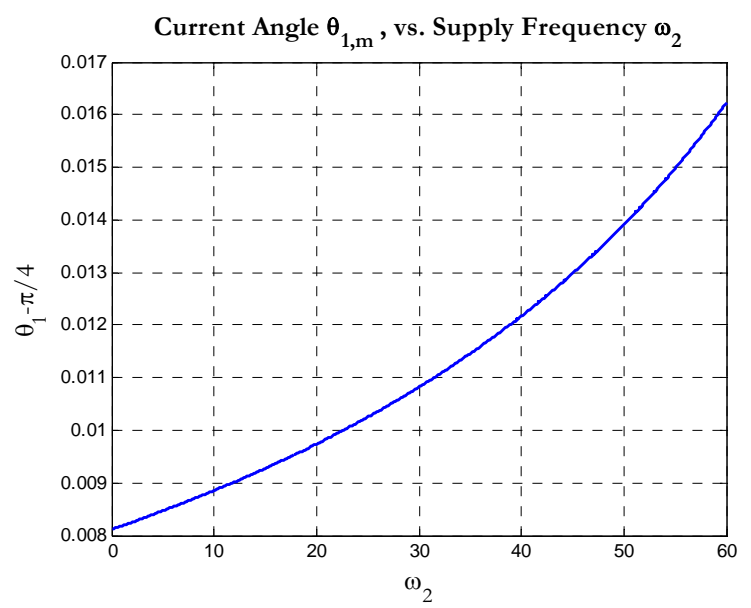

Fig. 7 Variation of stator current angel vs. control winding frequency

It is clear that the error of power winding current angel from 45 degrees is less than 0.5 degree.

\section{Machine design objective function}

The optimization process has another result inside. The asymptote of pick value of synchronous torque is comprised of stator current value and some design elements, as discussed before.

$$
\begin{gathered}
T_{\text {syn,max }}=\frac{I^{2}}{L_{r}} \frac{n_{1}}{n_{2}} M_{1_{1}} M_{2_{1}}\left|p_{2}-p_{1}\right| \\
\tau=T_{\text {syn,max }} / I^{2}=\frac{n_{1}}{n_{2}} \frac{M_{1_{1}} M_{2_{1}}}{L_{r}}\left|p_{2}-p_{1}\right|
\end{gathered}
$$

The parameter $\tau$ is now offered as a well-defined objective function for BDFM design optimization problems, in the sense of MTPA, or copper loss minimization either. This function comprises of magnetic design elements and pole pair numbers. The pole pair difference term indicates that the difference between pole pair numbers has a significant effect on torque; however all design issues should be considered together. All these parameters are extracted from BDFMs synchronous frame model as stated before.

\section{Conclusion}

In this paper, an analytical optimization process for torque of BDFM was presented. Scope of optimization was confined to copper loss in lack of the core loss model for BDFM. The uni-current proposition was presented for ease of analysis, consisting of three natural design and operation boundaries for machine. Using the uni-current proposition, the torque equation was simplified and divided into two parts, synchronous and asynchronous torque. It is shown that asynchronous part causes large torque deviations, but may be damped in proper speed intervals. This benefit is achieved by connection of lower pole number stator winding to grid. The final finding is a practical objective function for machine design optimization, which will improve machine efficiency. 


\section{References}

[1] P. Famouri and J. J. Cathey, "Loss Minimization Control of an Induction Motor Drive," IEEE Transactions on Industry Applications, Vol. 27, No. 1, 1991, January/February 1991, pp. 32-37.

[2] J. C. Moreira, T. A. Lipo, and V. Blasko, "Simple Efficiency Maximizer for an Adjustable Frequency Induction Motor Drive," IEEE Transactions on Industry Applications, Vol. 27, No. 5, 1991, September/October 1991, pp. 940-946.

[3] I. Kioskeridis and N. Margaris, "Loss Minimization in Scalar Controlled Induction Motor Drives with Search Controllers," IEEE Transactions on Power Electronics, Vol. 11, No. 2, 1991, March 1996, pp. 213-220.

[4] M. H. Park and S. K. Sul, "Microprocessor-Based Optimal-Efficiency Drive of an Induction Motor," IEEE Transactions of Industrial Electronics, Vol. 31, No. 1. February, 1984, pp. 390-394.

[5] I.T. Wallace, R.D. Lorenz, D.W. Novotny, D.M. Divan. "Increasing the dynamic torque per ampere capability of induction machines". In Proc. of IEEE-IAS Conf. Rec 1991 , pp. 14-20, IEEE Trans. on Ind. Appl. January/February 1994, pp.146-155.

[6] O. Wasynczuk, et. al, "A Maximum Torque per Ampere Control Strategy for Induction Motor Drives," IEEE Transactions on Energy Conversion, Vol. 13, No. 2, June 1998, pp. 163-169.

[7] A. Consoli, G. Scarcella, G. Scelba, S. Sindoni, A. Testa, "Steady-State and Transient Analysis of Maximum Torque per Ampere Control for IPMSMs",in Industry Applications Society Annual Meeting, 2008. IAS '08. IEEE Vol. pages 1-8, 5-9 Oct. 2008

[8] A. Troy, Nergaard, H. E. Kouns, J.-S. Lai and C. E. Konrad, "Optimal System Efficiency Operation of an Induction Motor Drive," in Conf. Rec. of IEEE IAS Annual Conference, Pittsburgh, PA, Oct. 2002, pp. 826 -831 .

[9] H. E. Kouns, and J.-S. Lai, and C.E. Konrad, "Analysis of a traction induction motor drive operating under maximum efficiency and maximum torque per ampere conditions". IEEE Applied Power Electronics Conference and Exposition. Vol. 1, 2004. Số trang: 545- 551.

[10] P. C. Roberts, R. A. McMahon, P. J. Tavner, J. M. Maciejowski, and T. J. Flack, "An equivalent circuit for the brushless doubly-fed machine (BDFM) including parameter estimation," Proc. IEE B - Elec. Power App., 2004, accepted for publication, November 2004.

[11] R.A. McMahon, P.C. Roberts, X. Wang, P.J. Tavner, "Performance of BDFM as generator and motor", IEE Proc. Elec. Power Appl., Vol.153, No.2, March 2006.

[12] Paul Roberts, "A study of Brushless Doubly-Fed (Induction) Machines", $\mathrm{PhD}$ Thesis, University of Cambridge, Cambridge, England, Sep. 2004.

[13] P. C. Sen, Principles of Electric Machines and Power Electronics, 2nd ed.: John Wiley \& Sons, 1997. 